\title{
Systems and Software Engineering Standards for Very Small Entities: Accomplishments and Overview
}

\author{
Claude Y. Laporte, École de technologie supérieure \\ Rory V. O'Connor, Dublin City University \\ ISO/IEC 29110 offers a customized set of standards and guidelines for very \\ small entities to guide their systems and software life-cycle activities and \\ thus improve their competitiveness in quality, cost, and schedule.
}

\begin{abstract}
A large majority of organizations very small entities (VSEs) - commercial, government, or not-for-profit organizations; departments; or projects with up to 25 people who develop systems with hardware and software components and/or software products. Their products are sold to their customers directly or are integrated into those developed by larger organizations, possibly distributed to thousands of users worldwide, as illustrated in Figure 1. A supply chain of large products often has a pyramidal structure composed of many first, second and third level suppliers. If an undetected defect is left in a low level component, once this component is integrated in a higher level component, the defect may still be undetected. This defective component, once integrated in the final product, could result in a loss of millions of dollars by the manufacturer.
\end{abstract}

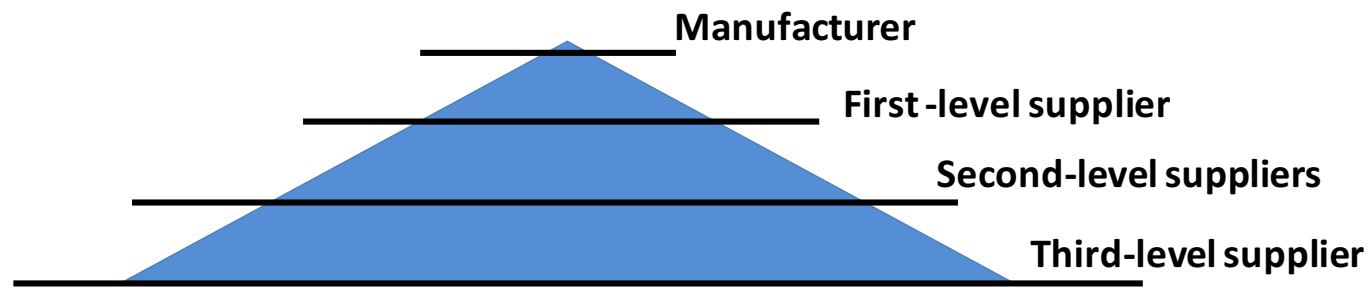

Figure 1. Example of a large manufacturer's supply chain.

Despite their importance in the global economy, VSEs generally don't utilize existing exhaustive practice standards such as ISO/IEC/IEEE 15288 and ISO/IEC/IEEE 12207, which focus on systems and software engineering life-cycle processes. These standards are seen as inappropriate, having originally been developed by large organizations unfamiliar with the specific needs of VSEs.

To remedy this, in 2005, the Thailand Industrial Standards Institute and the Thailand Software promotion agency sponsored a working group to kick-start a set of standards and guides targeting VSE needs. Subsequently, the ISO and the International Electrotechnical Commission (IEC) mandated a working group (WG24) to develop the set of ISO/IEC 29110 standards and guides. Australia, Belgium, Brazil, Canada, Finland, France, Germany, Ireland, Japan, Spain, the US, and Uruguay as well as many countries that hadn't previously participated in the development of ISO/IEC systems and software engineering standards-including Argentina, Colombia, the Czech Republic, India, Luxembourg, Mexico, Peru, and Thailand-decided to join WG24.

WG24 developed an international survey, which was translated into nine languages and disseminated in 28 countries. Results of this survey indicated that most VSEs didn't use existing standards because they lack the resources. In addition, such standards weren't required by customers or managers, were difficult to use, were perceived as being bureaucratic, and didn't provide adequate guidance for tailoring for use by VSEs. 


\section{IEEE Computer - July 2016 - Pre-Publication Version}

Respondents requested lightweight and easy-to-understand standards with examples, templates, and checklists. Many respondents also indicated that it was important for them to be either recognized or certified to increase customer confidence and their potential to export.

\section{WG24 STRATEGY}

Because the existing ISO/IEC SC7 portfolio of software and systems engineering standards was extensive, the working group decided to use elements of the portfolio to develop a four-stage road map, using ISO profiles, to serve the needs of VSEs. The generic profile group, applicable to the vast majority of VSEs that don't develop critical systems or critical software, is a collection of four profiles-Entry, Basic, Intermediate, and Advanced. Each profile is based on a set of VSE characteristics (business model, risk, and so forth) and presents a matrix that lists elements taken from existing standards such as activities, tasks and work products.

WG24 also decided to develop a set of documents targeted to specific audiences:

- an overview document defining the common terms and concepts in ISO/IEC 29110's set of standards and guides (see http://standards.iso.org/ittf/PubliclyAvailableStandards).

- a document specifying the elements common to all profiles, including structure, requirements, conformance, and assessment;

- a document defining certification schemes, assessment guidelines, and compliance requirements for process capability assessment, conformity assessments, and self-assessments for process improvements; and

- a document providing the specifications for a set of profiles that describe "what to do."

- a set of management and engineering guides that describe "how to" in detail.

One significant ISO member country rejected the need for a VSE-specific standard on the grounds that a well-known ISO/IEC/IEEE 12207 life-cycle standard already met all the needs of VSEs developing software. The assertion was that a VSE could select a subset of the ISO/IEC/IEEE 12207's processes that apply to its specific project, then tailor its requirements (that is, the "what to do") and document a set of "usable" processes (that is, the "how to") for VSE developers. However, based on the WG24 survey responses, an overwhelming majority of ISO/IEC member countries believed that VSEs weren't prepared to undertake that work and that there was indeed need for a VSE-specific standard.

\section{WORK OF WG24 MEMBERS}

A dedicated core team of WG24 members, supported by a larger network of interested parties, developed the first set of ISO/IEC 29110 documents. During five review cycles over a three-year period, WG24 processed more than 1,300 official comments submitted by member countries. Interestingly, many difficulties arose due to the diverse community of participants with different cultural perspectives (for instance, Eastern versus Western) speaking various languages. This added to the complications of developing an international standard, but it also contributed to the standard's truly international perspective. For example, there was some confusion about the meaning of the word system, because many countries use this term to refer to IT systems. The working group reduced this ambiguity by adding an explanation in ISO/IEC 29110's common introduction that, in this context, systems typically contain hardware and software components.

\section{THE BASIC PROFILE}

The ISO/IEC 29110 Basic profile targets VSEs developing a single application by a single team; it defines software implementation (SI) and project management (PM) processes, as illustrated in Figure 2. A customer provides a Statement of Work, or a description of the functionalities required within a specified 


\section{IEEE Computer - July 2016 - Pre-Publication Version}

timeframe and budget, as an input to the PM process. Then, a project plan guides the execution of software requirements analysis, architecture and detailed design, construction, integration and test, and product delivery activities. Finally, the PM process delivers to the customer the software configuration - that is, the complete set of software artifacts that comprise the product, including user documentation, code, and so on - and obtains the customer's acceptance to formalize the end of the project.

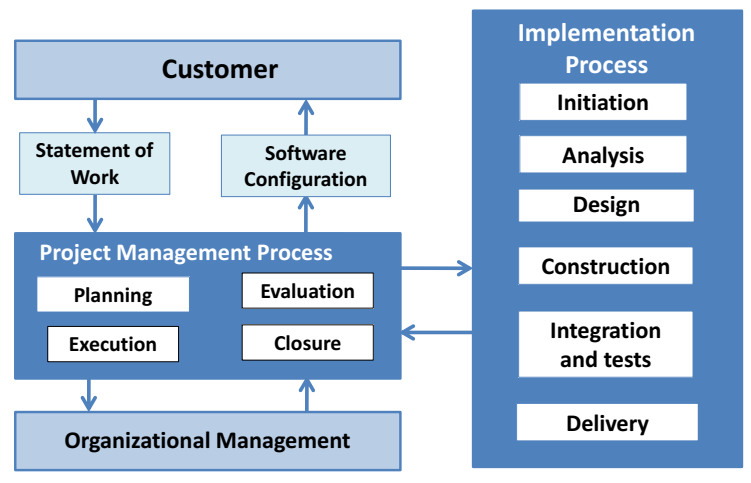

Figure 2. Activities involved in two software engineering basic profile processes.

Although the Basic profile might give the impression of a waterfall development cycle, the ISO/IEC 29110 series isn't intended to dictate the use of any particular life cycle, whether waterfall, iterative, incremental, evolutionary, or agile.

\section{ISO/IEC 29110 IN SYSTEMS ENGINEERING}

In 2011, WG24's original mandate was expanded to produce a set of documents for VSEs involved in systems development. This work has used selected elements from ISO/IEC/IEEE 15288. ISO/IEC 29110's Entry and Basic systems engineering management and engineering guides have been published; the Intermediate profile is presently being developed.

\section{DISSEMINATION AND ADOPTION}

Because VSEs might not have the resources to implement all the activities and tasks of a profile at the same time, WG24 developed a set of how-to guides, called deployment packages, that describe in detail the steps, checklists, and templates for implementing ISO/IEC 29110 practices. These are freely available in multiple languages (http://profs.logti.etsmtl.ca/claporte/English/VSE/index.html),

ISO systems and software engineering standards are normally published only in English. However, international demand for the ISO/IEC 29110 management and engineering guides became so great that they have been translated into Czech, French, German, Portuguese, Spanish, and soon Arabic.

Most VSEs don't regularly browse the ISO website in search of standards; therefore, diffusion mechanisms were developed to reach VSEs worldwide, including websites, YouTube and ISOPlanet videos, ISO/IEC 29110 multilingual pages on Wikipedia, articles describing implementation projects in start-ups, webinars, workshops, and conferences. Many articles were written to reach an international and diverse audience ranging from start-ups to well-established companies in automotive, medical, railway, finance, utilities, defense, and aerospace fields.

The fact that ISO/IEC 29110 guides are easily understandable and freely available has greatly helped their adoption; more than 15 countries are teaching it at the undergraduate and graduate levels. In Thailand, more than 10 universities teach ISO/IEC 29110, and in Canada, it's taught in software quality assurance and software process improvement courses. In addition, students are implementing ISO/IEC 29110 in 


\section{IEEE Computer - July 2016 - Pre-Publication Version}

undergraduate and graduate capstone projects.

Furthermore, ISO/IEC 29110 has been successfully implemented in VSEs in many countries, including IT start-ups in Canada, Peru, and in a VSE co-located in Tunisia and Canada; in a large financial institution; and in a large utility provider. Recently, the ISO/IEC 29110 systems engineering basic profile was successfully implemented and audited in a VSE involved in the design and production of subway system components.

VSEs that have implemented ISO/IEC 29110 management and engineering guides have improved in one or more aspects of competitiveness including quality, cost, and schedule. For example, projects using ISO/IEC 29110 for the first time had only 10 to 18 percent of rework as opposed to about 40 to 50 percent of rework typical of a majority of software developers.

The ISO/IEC 29110 framework is still young, but its use in VSEs and in educational institutions proves that WG24 reached its original set of objectives: developing standards and guides that VSEs can readily implement. ISO/IEC 29110 is such a promising standard that several countries, such as Brazil, Mexico, Peru, Japan, Thailand, and Uruguay, have adopted ISO/IEC 29110 as a national standard, and others have established government programs to motivate VSEs to implement ISO/IEC 29110 and obtain an ISO/IEC 29110 certification.

Claude Y. Laporte is a professor at the École de technologie supérieure of Montréal, and project editor of the ISO/IEC 29110 series of standards and guides. Contact him at Claude.Y.Laporte@etsmtl.ca.

Public web site of ISO 29110: http://profs.logti.etsmtl.ca/claporte/English/VSE/index.html

Rory V. O'Connor is a professor of computing at Dublin City University and a senior researcher with Lero, the Irish Software Research Centre. Contact him at rory.oconnor@dcu.ie. 